\title{
You Can Only Go Full Speed for So Long: The Career Development of Psychologists Working in Psychosocial Oncology Settings
}

\author{
Trisha L. Raque-Bogdan ${ }^{1}$ (D) Amanda Kracen ${ }^{2} \cdot$ Nicole E. Taylor $^{1} \cdot$ Ellen Joseph $^{1} \cdot$ Heather Engblom $^{1} \cdot$ Kaitlin Ross $^{1}$. \\ Taylor Michl ${ }^{2} \cdot$ Afton Nelson $^{2} \cdot$ Hannah Rowold ${ }^{2}$
}

Published online: 8 February 2019

(c) Springer Science+Business Media, LLC, part of Springer Nature 2019

\begin{abstract}
Cancer centers have adopted a holistic approach to cancer treatment to better meet the psychosocial needs of cancer survivors. However, the current number of psychosocial providers in oncology is inadequate to meet the growing demand and psychosocial providers may face barriers in accessing oncology-specific training. The current study aims to explore the career development of psychologists working in oncology to inform training and workplace supports, as well as to inform training for health psychologists interested in other sub-specialties. Interviews were conducted with 20 psychologists with oncology work experience. Data were analyzed using the consensual qualitative research method. Results indicated three primary domains: (a) factors influencing entry into the field, (b) factors influencing ongoing career decision-making, and (c) factors influencing success in psychosocial oncology. The complexities of these domains are discussed; suggestions for supporting psychologists interested in psychosocial oncology at individual as well as systemic levels are provided.
\end{abstract}

Keywords Psychosocial oncology · Training · Career development · Consensual qualitative research

Due to improved detection and treatment, the growing prevalence of cancer patients has been referred to as the "survivorship tsunami" (Mayer, 2018) with a projected 20.3 million cancer survivors in the United States by 2026 (National Cancer Institute, 2018). The emotional needs of cancer survivors have received increasing attention since the Institute of Medicine's report, Cancer Care for the Whole Patient (Adler \& Page, 2008), recommended a holistic approach to addressing the quality of life concerns of cancer patients and survivors. Further, distress screening has become mandated as part of accreditation standards by American College of Surgeons Commission on Cancer (CoC), with distress reported by up to 52\% of cancer patients (Mehnert et al., 2018). The field of psychosocial oncology is defined as

We presented an earlier version of this project at the American Psychosocial Oncology Society 2018 annual meeting. We would like to thank Dr. Mary Ann Hoffman for serving as auditor for this project.

Trisha L. Raque-Bogdan

tlraque@gmail.com; trisha.raque-bogdan@du.edu

1 University of Denver, Denver, CO 80208, USA

2 Webster University, St. Louis, MO 63119, USA ...a specialty area in cancer care concerned with understanding and treating the social, psychological, emotional, spiritual, quality-of-life and functional aspects of cancer, from prevention through bereavement. It is a whole-person approach to cancer care that addresses a range of very human needs that can improve quality of life for people affected by cancer (Canadian Association of Psychosocial Oncology, n.d.).

This may include psychosocial oncology providers helping cancer patients, survivors and caregivers manage treatment side effects, pain, fatigue, cognitive changes, depression, and anxiety.

As cancer centers adopt a more holistic and patientcentered approach to addressing cancer survivors' psychosocial needs, there has been increasing attention to the staffing and delivery of psychosocial services (Deshields, Kracen, Nanna, \& Kimbro, 2016). Psychologists are among the mental health professionals applying the biopsychosocial model to provide cancer care for the "whole patient" (Deshields \& Nanna, 2010; Turner, 2010). Psychologists work collaboratively with social workers, psychiatrists, nurses, chaplains, physicians, and oncologists as part of interprofessional teams, and psychologists 
may provide direct clinical care in the format of individual therapy, family and couples therapy, group therapy, and assessment; consultation with health care team members; program development and evaluation; training and supervision, and research (Deshields \& Nanna, 2010). Yet the number of psycho-oncology professionals, including psychologists, prepared to meet the needs of the ever-growing population of cancer survivors is inadequate (Hoge $\&$ Roth, 2015). Moreover, increasing the number of psychologists working in psychosocial oncology care may be complicated by the lack of a direct pathway into the field given that it is not a formally recognized specialty training area.

The American Psychological Association's (APA) Commission for the Recognition of Specialties and Proficiencies in Professional Psychology (CRSPPP) describes specialty areas as "a defined area of psychological practice which requires advanced knowledge and skills acquired through an organized sequence of education and training." Professional psychology is moving in the direction of increasing specialization, with concerns about the adequacy, availability, and quality of specialized training opportunities (Deshields \& Nanna, 2010; Neimeyer, Taylor, Rozensky, \& Cox, 2014). Clinical health psychology has been a recognized specialty since 1997, but there is no formal recognition by APA for psychosocial oncology as a specialty. Thus, there is no structured sequence of coursework, clinical practicums, and expected competencies for psychologists interested in working in oncology. Instead, psychologists entering psychosocial oncology settings may pull from clinical health psychology training to acquire the foundational knowledge of the

...interrelationships among behavioral, emotional, cognitive, social, and biological components in health and disease and the application of this knowledge to health promotion and maintenance, medical illness and disability prevention, treatment and rehabilitation, and healthcare system improvement...how learning, memory, perception, cognition, and motivation affect and are affected by physical illness, injury, and disability (Hoge \& Roth, 2015, p. 686).

Building upon on the identified competencies of clinical health psychology, those interested in oncology may then seek additional disease-specific knowledge and experiences in cancer care through practicums, pre-doctoral internship or post-doctoral fellowship positions (Hoge \& Roth, 2015). Some psychologists working in oncology may not have specific academic or supervised training and may rely on in vivo training and exposure in the workplace. Further, psychosocial oncology is a subspecialty within the umbrella of clinical health psychology. Thus, the career experiences of psychologists interested in oncology may mirror that of clinical health psychologists pursuing other subspecialties.
To explore the career development of psychologists working in psycho-oncology, we conducted a qualitative study with 20 psychologists who either were working or previously had worked in oncology settings. Information on the career development of psychologists in oncology is needed to inform trainee preparation, advising, supervision, mentorship, as well as workplace retention, and may have implications for the career development of psychologists in other sub-fields of health psychology. In this context, we have conceptualized career development as the dynamic and ongoing obtainment of job-related skills and knowledge, professional development, and career decision-making processes (Lent \& Brown, 2013). This paper focuses on the study findings that address the research questions of (a) how do psychologists make the decision to enter and remain in the field of psychosocial oncology, and (b) what contributes to their success in the field. Findings related to influences on their career development arose from the interview questions, and are incorporated accordingly. These findings represented one portion of a larger qualitative study, which is described by Kracen (2018).

\section{Method}

\section{Study Design}

Consensual qualitative research (CQR; Hill, Thompson, \& Williams, 1997; Hill et al., 2005) was implemented because it outlines a systematic qualitative methodology emphasizing achieving consensus through multiple perspectives of a research team and an external auditor. CQR aims to minimize individual researcher bias, and conceptualize qualitative data integrating multiple perspectives. Given that our research team was comprised of several members who are psychologists who formerly worked in psycho-oncology settings and currently work with cancer survivors in private psychotherapy practice, we thought it was critical to utilize a qualitative approach that structurally addressed the potential influence of researcher bias to help protect against the researchers' personal experiences with the research topic from unduly influencing the coding results. For this study, two coding teams at two different universities collaborated to implement the CQR steps (outlined below). CQR has been previously utilized in a multitude of studies examining career development, including the career paths of psychologists (e.g., Duffy et al., 2012).

\section{Research Ethics Review}

The Institutional Review Board at Webster University granted approval for the current study, resulting in exemption status from the University of Denver. Participants were 
not provided with compensation for their participation and informed consent was collected prior to interviews.

\section{Sample Selection and Characteristics}

\section{Participants}

Participants were recruited through both purposeful and snowball sampling. More specifically, the study announcement was (1) posted to listservs of the American Psychosocial Oncology Society, American Psychological Association Division 38 (Health Psychology), and Society of Behavioral Medicine, (2) disseminated via email to colleagues of the principal investigators who may be eligible for the study, and (3) advertised in person at the American Psychosocial Oncology Society annual conference in March 2016. Interested participants were directed to an online Qualtrics survey for informed consent and to gather demographic background information. The purpose of the current study was explained as an exploration of "factors that have influenced the career development of psychologists who are currently working in psycho-oncology or who previously worked in the field of psycho-oncology." Interview procedures, transcription procedures, potential risks, confidentiality, data protection, and inclusion criteria were also explained. To participate in the study, participants had to (a) be over the age of 18 years, (b) have a Psy.D. or Ph.D. in psychology, and (c) currently work in psycho-oncology or have previously worked in psycho-oncology within the last 5 years. Interested participants who met the inclusion criteria and provided consent then completed a demographic survey and provided their contact information for scheduling a phone interview.

Twenty-one participants met all inclusion criteria, provided consent, and agreed to be interviewed. Of those, 20 completed the interviews and 1 did not due to scheduling conflicts. We originally sought ten psychologists currently working in psychosocial oncology, and ten psychologists who had worked in the field in the last 5 years but have since left the field. We found that the boundary between being "in" and "out" of the field was challenging to define, as many participants remained involved in some aspect of cancer care (e.g., part-time private practice with cancer survivors or consultation work with cancer treatment centers) after leaving full-time psycho-oncology positions. Thus, we have reported the results for all 20 participants as one sample. Participant characteristics are displayed in Table 1 . To protect participants' anonymity, demographics are only reported for the group rather than for individuals. Participants' $(N=20)$ ages ranged from 31 to 63 . All identified as licensed psychologists, with 13 self-identifying as still working in the field of oncology and 7 psychologists who self-identified as having left the field of psycho-oncology within the last 5 years. For those who indicated that they did not work in academic
Table 1 Participants' demographics and occupational background

\begin{tabular}{|c|c|c|}
\hline Demographic characteristic & $\begin{array}{l}\text { Number } \\
(N=20)\end{array}$ & Percentage \\
\hline Worked in psycho-oncology in last 5 years & 7 & 35 \\
\hline Works in psycho-oncology currently & 13 & 65 \\
\hline \multicolumn{3}{|l|}{ Gender } \\
\hline Men & 5 & 25 \\
\hline Women & 15 & 75 \\
\hline \multicolumn{3}{|l|}{ Age } \\
\hline $31-40$ & 10 & 50 \\
\hline $41-50$ & 5 & 25 \\
\hline $51-60$ & 3 & 15 \\
\hline $61-69$ & 2 & 10 \\
\hline \multicolumn{3}{|l|}{ Racial/ethnic background } \\
\hline White & 18 & 90 \\
\hline Hispanic or Latino/a & 1 & 5 \\
\hline Asian/Pacific Islander & 1 & 5 \\
\hline \multicolumn{3}{|l|}{ Graduate degree } \\
\hline $\mathrm{PhD}$ & 14 & 70 \\
\hline PsyD & 6 & 30 \\
\hline \multicolumn{3}{|l|}{ Field } \\
\hline Counseling psychology & 4 & 20 \\
\hline Clinical psychology & 16 & 80 \\
\hline \multicolumn{3}{|l|}{ Years worked in psycho-oncology } \\
\hline $0-5$ & 5 & 25 \\
\hline $6-10$ & 8 & 40 \\
\hline $11-15$ & 4 & 20 \\
\hline $16+$ & 3 & 15 \\
\hline \multicolumn{3}{|l|}{ Age group worked with } \\
\hline Adults & 18 & 90 \\
\hline Both adults and pediatrics & 2 & 10 \\
\hline \multicolumn{3}{|c|}{ Percentage of time spent in direct patient/caregiver care } \\
\hline $0-20 \%$ & 7 & 35 \\
\hline $21-40 \%$ & 1 & 5 \\
\hline $41-60 \%$ & 4 & 20 \\
\hline $61-80 \%$ & 4 & 20 \\
\hline $81-100 \%$ & 4 & 20 \\
\hline \multicolumn{3}{|l|}{ Current workplace } \\
\hline Academic medical setting & 9 & 45 \\
\hline Other & 11 & 55 \\
\hline
\end{tabular}

medical settings, they reported working in VA hospitals, community cancer centers, private practice, and outpatient cancer or community health centers.

\section{Research Team}

The research team was comprised of nine individuals from the University of Denver and Webster University, ranging in age from 21 to 42 , one identifying as gender expansive and the others identifying as cisgender women, and all 
self-identifying as White. The three principal investigators are university faculty members (an assistant professor in a counseling psychology program, a clinical associate professor in a professional psychology program, and an assistant professor in an undergraduate psychology department). At the time of the study, three team members were doctoral students in counseling psychology programs and three members were undergraduate students studying psychology or women, gender, and sexuality studies. All coding team members participated in a CQR training led by the first author.

\section{Data Collection}

\section{Demographic Form}

The demographic questions asked participants about age, gender, racial/ethnic background, current relationship status, graduate degree, licensure status, and training experiences in psycho-oncology. The participants were also asked questions about their current occupation, including their current status in the field, current work setting, years worked in the field, patient demographics, and clinical hours.

\section{Interview}

Interviews were conducted by the second and third authors using a semi-structured protocol assessing 11 questions (the interview protocol is located in the Appendix), with the themes related to career development reported here. The interview protocol was developed after reviewing the literature available on the training of psychologists working in oncology (e.g., Hoge \& Roth, 2015). The interview questions related to career development include: (a) How did you choose to work in psycho-oncology? (b) How have mentors influenced your career path? (c) What were some key training experiences that prepared you for the field of psycho-oncology? (d) How have your personal career goals or aspirations evolved? (e) What will help you stay in this career long term? and (f) What would influence your choice to stay or leave the field? Participants were provided with the interview questions via email prior to the interview to familiarize themselves with the discussion topics. All interviews were conducted over the phone as recommended by CQR to allow for greater participant anonymity when disclosing personally and professionally sensitive information (Spangler, Liu, \& Hill, 2012). Interviews lasted between 25 and 65 min.

\section{Transcription}

All interviews were audio recorded. The student research team members transcribed the interviews, and the transcripts were then sent to the participants to review and amend any responses as they deemed necessary. Two participants suggested minor revisions, which were made to their transcripts prior to analysis.

\section{Analysis Strategies}

\section{Coding}

Data were analyzed using the CQR method (Hill et al., 1997, 2005). Because the coding team was split across two universities, the group was divided into two respective coding teams. Both teams participated in each step of the CQR process by holding weekly in-person team meetings at each respective university, and then having collaborative monthly telephone meetings with both coding teams to arrive at consensus for each level of coding.

CQR data analysis involves three levels of coding in which domains, core ideas, and categories are constructed. The first level of coding, or the construction of domains, aims to capture the most broad topic areas across all interviews. Team members from both coding teams read one transcript in its entirety and developed a list of potential domains in their respective university-based teams. Only data that related to career development and future career plans and aspirations are reported in the current study. Each team took turns in identifying domains, which were then reviewed by the other teams. Both coding teams held meetings to arrive at consensus.

The second level of coding, or the construction of core ideas, aims to summarize the content of each participant statement. Initially, each university-based team divided into pairs to review each transcript and develop core ideas, presenting their core ideas to their respective university-based team for review. Similar to the process for creating domains, core ideas created by each university-based team were then reviewed by the other coding team, and discussion continued until all coders achieved consensus.

The third level of coding, or cross-analysis, aims to review the core ideas across all participant interview data. The same process was implemented for cross-analysis as was utilized in earlier stages of coding. After each university-based team reached consensus, they shared their results with the other team to develop a final list of categories that appropriately represented all interview data.

\section{Auditing}

As outlined in the CQR method (Hill et al., 1997, 2005), the research team included an independent external auditor to provide feedback at each step of the coding process. The auditor was a full professor in a counseling psychology graduate program with expertise in the $\mathrm{CQR}$ method as well as psycho-oncology. The auditor's feedback at the level of domains, core ideas, and cross-analysis was reviewed among 
the entire research team and discussed until consensus was reached. This feedback was incorporated into the final list of domains, core ideas, and categories.

\section{Results}

Three primary domains emerged from the qualitative interviews: (a) factors influencing entry into the field of psychosocial oncology, (b) factors influencing ongoing career decision-making, and (c) factors influencing success in psychosocial oncology. Table 2 displays the domains, categories, and subcategories, and their frequency. General was used for themes endorsed by 19-20 participants, typical for those endorsed by 11-18 participants, variant for those endorsed by 4-10 participants, and rare for those endorsed by 2-3 participants (Spangler, Liu, \& Hill, 2012). We discuss the results from the three primary domains with illustrative quotes in the following sections.
Table 2 Summary of domains and categories

\begin{tabular}{|c|c|}
\hline Domains and categories & Total $(N=20)$ \\
\hline \multicolumn{2}{|l|}{ Factors influencing entry into the field of psychosocial oncology } \\
\hline Fell into the field & Typical (14) \\
\hline General interest in health & Typical (17) \\
\hline Initial exposure & General (19) \\
\hline Contact with cancer in broader medical settings & Typical (13) \\
\hline Research & Variant (9) \\
\hline Pre-doctoral internship & Typical (11) \\
\hline Post-doctoral fellowship & Variant (7) \\
\hline Cancer-related professional conferences & Rare (3) \\
\hline Coursework & Rare (3) \\
\hline Path driven by unmet needs & Typical (15) \\
\hline Personal experience with cancer & Variant (10) \\
\hline \multicolumn{2}{|l|}{ Factors influencing ongoing career decision-making } \\
\hline Importance of professional relationships & General (20) \\
\hline Mentors & Typical (18) \\
\hline Supervisors & Typical (13) \\
\hline Colleagues & Variant (6) \\
\hline Patients & Rare (3) \\
\hline Prominent Figures & Rare (3) \\
\hline Family influences & Variant (8) \\
\hline Career curiosity and flexibility & General (20) \\
\hline Goals changed & Typical (11) \\
\hline More openness to career options & Variant (7) \\
\hline Unexpected achievement & Variant (5) \\
\hline \multicolumn{2}{|l|}{ Factors influencing success in psychosocial oncology } \\
\hline Emphasized need for ongoing training & General (19) \\
\hline Sees cross-over between psycho-oncology and other health psychology experiences & Typical (11) \\
\hline Expresses desire for more formalized oncology-related training & Rare (2) \\
\hline Expresses desire more broad training & Variant (6) \\
\hline Self-initiative & Variant (7) \\
\hline Conferences/workshops & Variant (5) \\
\hline Had to learn to set boundaries & General (20) \\
\hline Processing vulnerabilities & Variant (9) \\
\hline Restructuring external boundaries & Typical (15) \\
\hline Managing emotional experiences & Typical (12) \\
\hline
\end{tabular}




\section{Factors Influencing Entry Into the Field of Psycho-oncology}

This domain referred to how interviewees described their pathway to entering the field of psycho-oncology. Participants discussed "falling" into the field, a general interest in health psychology, a variety of initial or key factors that influenced their entry into the field, and an awareness of an unmet need in the field.

Interviewees noted that they had "fallen" into the field as an accident, due to happenstance with a lack of intentionality and without a clear "traditional" career trajectory initially. One participant expressed this as, "So, it was a combination of things and none of them necessarily thought out or planned out initially... sort of serendipitous and then at some point there was a choice piece in that as well." Several participants recounted multiple unplanned factors that influenced their career path leading into oncology and led them to feel that the field had "chosen them."

Interviewees expressed having a general interest in health psychology broadly. A participant described this as,

I went in with the intention that I knew I needed to be in a medical setting. I wanted to be in a type of field of psychology where it was medically focused. And then the oncology part was kind of in the back of my brain and then later on it kind of fell into place.

When considering the key experiences that exposed them to the field of psychosocial oncology and influenced their desire to specialize in the field, interviewees noted the importance of research, coursework, and cancer-related professional conferences or workshops, contact with cancer within broader medical settings such as at VA hospitals, and clinical health psychology pre-doctoral internship and postdoctoral fellowship experiences that incorporated rotations in oncology. An interviewee captured this as,

I started my graduate training with an interest in general health psychology, so that was always a strong interest of mine. I did training in primary care psychology and my internship was in the VA system... some of my mentors on internship would say to me pay attention to what energizes and excites you as you're training, and, I noted throughout my internship year that what I was really enjoying were those inpatient medical consults where I was doing work bedside, and often the veteran had a medical diagnosis and there were a few occasions where I met with veterans that had just received a cancer diagnosis. So I kind of got exposed to psycho-oncology initially that way, and really alongside that throughout internship year I was learning much more, I was also doing home-based primary care work. Often the veterans were, some of them had very advanced or complex illnesses, so I was also learning a lot more just about palliative care and through that my interest really sparked and, when I was thinking about postdoc experiences, I thought about trying to get more experience in psycho-oncology/ primary care.

Four of the interviewees identified only one key initial experience that exposed them to psycho-oncology, whereas the remaining 14 interviewees noted multiple influences on their entry into the field.

Participants noted that they were influenced to enter psycho-oncology due to an awareness of unmet needs within the field. These unmet needs included those of patients and families affected by cancer, as well as recognition that there was a need to bridge fields such as public health, psychology, and oncology to best meet patients' concerns. One interviewee whose previous work as a nurse influenced their entry into the field of psycho-oncology noted,

And I was very comfortable in the medical environment and one of the things that had been really obvious to me when I was a nurse was how often the patient and families' psychological, emotional, mental wellness was at least as and a lot of times more important than what they were going through medically. And there wasn't that much help for people who were inpatients back in my nursing years and I came away knowing that people who have major health problems are very distressed and often so are their families.

Additionally, personal or family experience with cancer that shed light on the need to address the emotional impact of the disease and inspired their career paths was reported by half of the participants. One interviewee expressed this as,

So my decision was actually inspired by a family member who had cancer. And this was prior to going to graduate school, I observed her going through the diagnosis and treatment and the surgery and really it was a residual, emotional impact and physical impact afterward that she struggled with.

\section{Factors Influencing Ongoing Career Decision-Making}

The domain of factors influencing ongoing career development contained categories that interviewees identified as important for affecting their career path after they had made the decision to work as psycho-oncologists. Career development involves how individuals plan and approach decisionmaking regarding their ongoing career activities, and may include external factors, such as the work environment or available systems of social support, as well as internal factors from within the individual. 
Generally, interviewees considered professional relationships as integral to their career development, with these interprofessional relationships connecting them with opportunities, inspiring them to develop a vision of what could be achievable within psycho-oncology, and infusing in them a confidence in their abilities to make a difference for their patients. Mentors in the areas of clinical work and research were typically considered critical, such as when one interviewee stated, "So I think mentors have also really influenced me in thinking about what I want in my career and how I want my career to fit into my overall life and lifestyle." Other interviewees noted the importance of mentors attending to the emotional intensity in oncology-related work as influencing their belief that they could enter and remain in the field. One interviewee expressed this as,

Because oncology is so complicated and complex not only in the clinical presentation, medical-clinical as well as psychological-clinical presentation, but as a clinician it's so difficult and complicated and emotional and exhausting and refreshing... so being in oncology and having her as a mentor was very grounding and she taught me a lot about how to be in such an emotionally difficult place and just try to quiet my reactions as much as I can and sit with them and learn through them and grow through them instead of feeling them or maybe being embarrassed or ashamed or trying to be perfectionistic. And I couldn't have grown in the way that I did without having her as a mentor to guide me and show me how to do that. And I think that I trusted her because she had done it for so long, where again it's that mentorship piece like seeing how someone could stay in such a difficult environment for such a long time, how did she do it? What does it take? What sorts of things do I need to do to be able to stay invested and stay present? And so her mentorship has really meant the world to me.

A few interviewees identified relationships with supervisors, patients, and prominent figures in the field (e.g., Jimmie Holland, described as the founder of the field) as key. Colleagues, including psychiatrists, oncologists, nurses, and social workers, were reported to be important influences on interviewees' career development.

All interviewees reported that their career development was characterized by curiosity and flexibility. They noted the need to remain open to the evolution of work activities and career goals when working in psycho-oncology, describing how their initial career goals had changed over time and experiencing unexpected achievements within the field as they were promoted into leadership positions. An interviewee expressed this as, "I certainly never saw myself being in leadership so young. I'm out of grad school 10 years and I think I envisioned that I would be a clinician for probably forever. I never saw myself taking this career path.” Other examples of altered paths include changing trajectory in psycho-oncology to more clinical or more administrative career paths to meet the needs of their workplace. Interviewees noted that once others on their interprofessional teams became aware of the psychologists' unique skill set, colleagues began to look to psychologists to shape the direction of their center's oncology services.

Interviewees also noted the role that family played in shaping their career paths since they entered the field of psycho-oncology. These family influences included partners' career prospects, childcare roles and responsibilities, and immigration status of the interviewees or their partners. One participant illustrated this category with the statement that, "Even my career path was a little bit meandering early on which was really due to circumstance because I got married and my husband took a job in a city where there really weren't many positions."

\section{Factors Influencing Success in the Field}

This domain represented interviewees' perspectives on factors that they believed were important for all psychologists to be successful in the field of psycho-oncology; they spoke of these categories in general terms as they would be helpful considerations for all psychologists interested in working in the field of oncology. Generally, interviewees emphasized the need for ongoing training to be successful psychooncologists. They noted that there were skills that crossed over from other health psychology training experiences (e.g., primary care, geriatrics, pain clinics) to psycho-oncology. Moreover, some conveyed the importance of broad training experiences in areas such as business administration and trauma work; one interviewee stated, "If I could have had more training on dealing with the business aspects, billing within the medical environment, just how to run a business, that would have been really helpful." Interviewees expressed the necessity of adopting an interprofessional perspective to psycho-oncology and recognized the need to integrate multiple skill sets from a variety of disciplines to be effective.

Interviewees described the importance of taking initiative on one's own to acquire the foundational knowledge base and skill set for psycho-oncology, including through conferences, workshops, and continuing education opportunities. One interviewee conveyed this as, "I have to say I have done some really nice pre-conference workshops through American Psychosocial Oncology Society (APOS) and International Psychosocial Oncology Society (IPOS). That, in terms of my continuing education, that's really the heart of it." A few interviewees noted the need for more formalized psycho-oncology-specific training.

The second category within this domain was about the need to set boundaries with oncology team members, while 
simultaneously taking care of their own emotional reactions to cancer. All interviewees endorsed this category. One interviewee described this as,

And I kind of have this image in my head being a piece of bread at the beach. All these pages [alerts from other providers] are like seagulls flying in and they were always taking but they were never replenishing. So I felt very torn and very like depleted. And then I was like, oh well then I'm really useless... so learning to set boundaries and assess and also train the multidisciplinary team how to handle patients just being distressed where they can help and have some active listening or some empathetic listening skills versus it really being a mental health crisis where a psychologist is needed. I think that and having that boundary of there will always be another patient to go see. And so having that boundary of like, "OK. I have to leave at some point today. Like I have to have closure to this."

Interviewees expressed the importance of identifying coping strategies for the emotional intensity inherent in oncology to avoid burnout in the field. One interviewee captured this as,

When I very first started, after about a year to a year and a half in this career, it suddenly hit me one day that is seemed like I had been sad for a really long time, and I started wondering, am I depressed, what's going on? And I thought about it, journaled about it, and all of a sudden it was like a light bulb went on for me. I suddenly realized that I was grieving the loss the death of every single patient... that died while I was caring for them. And I suddenly realized that, since I started this job, I'd not been grieving, and I suddenly realized that I'm going to have to do this differently... Once I grappled with that, I resolved the grieving and realized how to do it and keep going without it impacting my own life, my mood, and since then I can't honestly say that I have had any great personal challenges doing this work. I love it; I really really think it's a very good fit for who I am and where I've come from in my life, and it's quite smooth personally for me.

For some, this self-care involved personal therapy, reflection on existential issues, and other tools for creating space to attend to one's internal experiences while working with cancer. An interviewee conveyed this as,

I think we always talk about work-life balance. I think all psychologists talk about that in any field. I think in this one it's especially important. And the self-care and for me I actually did my own therapy when I was in graduate school as part of exploring my own stuff but also to practice self-care during a very stressful time. And so I think if someone's going into psychooncology I almost feel like it should be mandatory or it should be highly encouraged to get your own selfexploration because the work is very rewarding but very demanding as well.

Interviewees noted the need to process the personal vulnerabilities that arise from working in psycho-oncology with another person working in the field, whether they be a supervisor, mentor, or colleague. An interviewee expressed this as,

This is very emotionally draining work and I think it's important to have a team environment where there's an awareness of that and there's support for self-care and there's venues whether with colleagues in psychology or another discipline to talk about situations that are difficult so that you can get some feedback in terms of how to manage the fatigue that can come along with the emotional or some people call it "compassion fatigue" that comes along with doing this kind of challenging work.

The third subcategory within the category on the need to set boundaries related to how interviewees' attempts to achieve a work-life balance necessitated the structuring of clear boundaries between work and home life. An interviewee stated,

Then also balancing that out with the goals of personal goals, parenthood, and mothering, and wanting to be available to my children and wanting to be doing well professionally and knowing that sometimes, you know that pursuing both of those things at the same time is tough... recognizing that you can only go full speed for so long and something has to give along the way and sometimes it's work and sometimes it's home.

\section{Discussion}

This study addresses the research questions of how psychologists make decisions about their career paths into the field of psycho-oncology, and the factors influencing their success in the field. We found that training structures, unmet needs within the field, personal experiences with cancer, and happenstance were influential to career entry into psychooncology. Additionally, interviewees emphasized the importance of ongoing training opportunities, relational factors, career curiosity and openness, and attending to the emotional intensity inherent in psycho-oncology as critical for ongoing career development and success.

The findings in the present study reflect the lack of formally structured specializations in psycho-oncology, and the importance of attending to both broad and specialized 
training for professional psychologists. These findings may also relate to the experiences of other clinical health psychologists pursuing sub-specialty areas. Durbin introduced the concept of "half-life of knowledge" in 1972, and Neimeyer et al. (2014, p. 92) defined this as "the time it takes a practicing professional, in the absence of any new learning, to become roughly half as knowledgeable or competent to practice." Clinical health psychology, as a specialization, was identified as having the shortest half-life of any psychology specialization, with it estimated as 7.3 years currently and projected to decrease to a half-life of knowledge of 5.3 years over the next 10 years (Neimeyer et al., 2014). Such projections indicate the ongoing need for psychologists interested in working in psycho-oncology to continually enhance their knowledge base, with clinical health psychology training as well as oncology-specific training (Deshields \& Nanna, 2010). The same conclusion may hold true for clinical health psychologists pursuing other subspecialties, although this warrants further exploration to support this extension of the current study's findings. Regardless, interviewees in the current study echoed this need for training opportunities, both as they were entering the field and as they progressed in their career trajectories.

The need for ongoing training in psycho-oncology may take on even more importance as there is no formal training or certification in the field. As a potential first step to provide structure to psycho-oncology training, models for assessing competency in this area could build off clinical health psychology competencies (France et al., 2008; Kerns, Berry, Frantsve, \& Linton, 2009), and reflect the importance of keeping pace with rapid advancements in healthcare. As reflected by our interviewees, advanced training that attends to healthcare's financial structures and policies, as well as the intersection of medical treatment with psychological well-being, may be especially relevant. The expertise demanded of psychologists working in oncology settings is rapidly expanding to include administrative, financial, business, and managerial skills as well as a greater level of understanding of the medical complexities of burgeoning cancer treatments.

In our study, the psychologists described that they were readily able to see connections between their prior training experiences in other health psychology settings and to transform that into confidence that they could be successful working in oncology. Though our participants reported some transferability of their previous clinical health psychology experiences once they entered oncology, they expressed the desire for more broad training in areas such as hospital administration, business management, and psychotherapy process and outcome research to help them advance in their current roles in psycho-oncology.

The fact that psychologists in psycho-oncology must seek out training opportunities may actually exacerbate the demands of working in the field, particularly as graduatelevel training in psycho-oncology is not standardized or required, nor is certification available. More broadly, the importance of being clear on expectations, such as for the requirement for ongoing training, has been identified as important for the retention of behavioral health providers (Little, 2017); clear communication about the training demands for entering psycho-oncology is needed. Moreover, cancer centers may consider integrating such trainings into their job responsibilities and compensation structures. Increasing the structural support through offering in-house training opportunities, such as continuing education, and incorporating these training experiences into recognized work hours, as opposed to trainings expected to be completed outside of regular work hours, may reduce that pressure for self-initiation and seeking external resources.

In addition to the structure of training experiences, interviewees in the present study described the importance of being open to career possibilities and cultivating curiosity as career opportunities arise. Working in psychosocial oncology, as the field currently exists, may warrant comfort with ambiguity and flexibility in how their roles may evolve. Definitions of flexibility encompass remaining aware of options, being open to adapt, having the skills to adapt, and learning from past experience to adapt (Karoly, 1991; Martin \& Rubin, 1995). In a study with Canadian government workers, Ito and Brotheridge (2001) found that career uncertainty was predictive of emotional exhaustion, and that career flexibility was a key coping mechanism when facing uncertainty in one's work. Career development research has found that flexibility may stem from intrapersonal factors, such as greater self-awareness and the ability to develop transferable skills (Weick \& Berlinger, 1989), as well as interpersonal and external factors, such as family-friendly workplace policies (Villablanca, Beckett, Nettiksimmons, \& Howell, 2011). Although more research is needed to identify the most significant predictors of the career flexibility for psychosocial oncologists, it is noteworthy that this was an aspect of career development interviewees emphasized and is congruent with the broader body of career development literature in its importance for managing career uncertainty.

Interviewees described one influence for their entry into the field as the recognition that cancer survivors' needs were not being fully met as a result of healthcare providers not practicing integrated models; they described how the helping fields attending to physical and mental health could join forces more fully to adopt a holistic approach to meet the needs of cancer patients and their families. Further, personal experience with cancer was identified as an important career influence. Given the prevalence of cancer, there is a high likelihood that the majority of psychologists will be affected by the disease-personally or within their family or social network-at some point in their careers. 
There may be aspects of the sense of meaning and purpose coming from that personal connection to cancer that enhance work well-being. Yet as noted in the literature on feeling called to a career (e.g., Duffy et al., 2012), sometimes feeling work serves a purpose can be detrimental. Specifically, seeing work as socially important may lead some to remain in less than ideal work settings.

One aspect of the career development of psychologists in psycho-oncology that was emphasized by interviewees was the need to set boundaries when working on interprofessional teams and attend to the emotional experiences inherent in working with cancer. Participants emphasized inwardly focused coping strategies, such as personal therapy, and external workplace resources, such as consultation, supervision, or opportunities to train other healthcare providers to also be able to provide basic emotional support to patients. Moreover, interviewees' references to the need to restructure their external boundaries suggests the importance of creating space for how working with cancer not only affects what one does in their work with patients, but also for how the work changes the psychologist on a more personal level. Addressing the ways in which working in the field affects psychologists personally may be important for supporting their work well-being.

\section{Implications for Psycho-oncology Training and Workplace Retention}

When considering the implications of this study's findings for psychologists' approaches to their work with trainees interested in psycho-oncology settings, it may be helpful to pull from research findings on career curiosity and flexibility, and feeling as if one fell into the field. Advisors, supervisors, and mentors can work with their health psychology trainees to be flexible and open to unplanned clinical and research experiences that may spark an unforeseen career interest. Further, after identifying expected competencies for psychologists interested in psycho-oncology, training programs and accrediting bodies can explore how to develop opportunities to acquire those competencies.

Moreover, advisors, supervisors, and mentors can attend to the reasons that trainees are interested in the field of psycho-oncology, and whether any personal connections to cancer will inspire trainees to remain committed to working in the field, even in the face of ambiguous career trajectories. Alternatively, advisors, supervisors, and mentors can help trainees consider how their personal connections to cancer may make them susceptible to sacrificing their personal well-being because of that personal sense of meaning and desire to improve conditions for cancer survivors. Given that we found that managing emotional experiences was considered important for being successful in the field, developing tools early in training for managing the emotional intensity of the work may be key for retention. Extending the growing body of research on helping oncology professionals identify how to manage difficult emotions across their career, advisors, supervisors, and mentors may help trainees learn to validate their grief reactions to cancer, identify spaces (and create them as needed) for recognizing, labeling, and reflecting on their emotions; and access resources for processing their feelings (Granek, Economou, Ferrell, \& Bhatia, 2007). Mindfulness, selfcare, and other stress-management strategies have been effective for addressing the emotional intensity of the work and fostering wellness among oncology healthcare providers (Medland, Howard-Ruben, \& Whitaker, 2004).

In addition to individual level factors that may relate to success in the field, interviewees indicated the importance of factors related to the work environment (e.g., access to training). Supervisors and mentors can work to improve psycho-oncology work environments, whereas advisors can help trainees assess the workplace conditions when trainees are deciding whether to pursue specific psycho-oncology positions. In short, change is needed at the level of the individual psychologist as well, as at the systemic level by addressing the structure of training and the workplace environment.

\section{Conclusion}

This qualitative study with 20 psychologists with work experience in psycho-oncology settings identifies the potential pathways for entering the field, the importance of curiosity, flexibility, relational influences, and ongoing training opportunities when working in a field that is evolving to meet the needs of cancer survivors, and the necessity of creating resources for attending to the emotional intensity of working in cancer care. As we strive to support even more cancer survivors, the role of psychologists is critical. Improving access to training opportunities, clarifying the process of entering and staying in the field, and bolstering resources for career flexibility and career decision-making in psycho-oncology will be essential to enhancing and expanding the workforce.

\section{Compliance with Ethical Standards}

Conflict of interest The authors Trisha L. Raque-Bogdan, Amanda Kracen, Nicole E. Taylor, Ellen Joseph, Heather Engblom, Kaitlin Ross, Taylor Michl, Afton Nelson, Hannah Rowold declare that they have no conflict of interest.

Ethical Approval All procedures were in accordance with the ethical standards of the institutional research committees and with the 1964 Helsinki declaration and its later amendments or comparable ethical standards. 
Informed Consent Informed consent was obtained from all individual participants included in the study.

\section{Appendix A}

\section{Psycho-oncology Career Development Interview Protocol}

1. How did you choose to work in psycho-oncology?

2. How have mentors influenced your career path?

3. What were some key training experiences that prepared you for the field of psycho-oncology?

a. What would have improved your training?

4. What (were) do you view as the biggest rewards of working in this particular career?

5. What aspects of your job provide(d) a sense of personal meaning?

6. What (were) do you view as the greatest challenges of working in this particular career?

a. Follow up with prompts for both personal and professional/organizational challenges.

b. How do (did) those challenges affect your thoughts about leaving the field?

c. FOR THOSE WHO LEFT: How did you decide to leave your work/job in psycho-oncology?

7. How do you maintain a professional identity? (What is your current professional identity, and how do you maintain it?)

8. How have your personal career goals or aspirations evolved?

a. Follow up with question related to transitions, if necessary (e.g., What are the biggest transitions you have experienced in your career? or How has your career evolved?).

9. What will help you (could have helped you) stay in this career long term?

a. What can (could) your employer do (could have done) to ensure your well-being/satisfaction in the field?

10. What would influence your choice to stay or leave the field?

11. If you were talking with a graduate student considering a career in psycho-oncology, what advice would you offer to them?

12. Is there anything else you would like to add?

\section{References}

Adler, N. E., \& Page, A. E. (2008). Cancer care for the whole patient: Meeting psychosocial health needs. Washington, D.C.: National Academies Press.

Bandura, A. (1982). The psychology of chance encounters and life paths. American Psychologist, 37, 747-755.

Deshields, T., Kracen, A., Nanna, S., \& Kimbro, L. (2016). Psychosocial staffing at National Comprehensive Cancer Network member institutions: Data from leading cancer centers. Psycho-oncology, 25(2), 164-169. https://doi.org/10.1002/pon.3826.

Deshields, T. L., \& Nanna, S. K. (2010). Providing care for the "whole patient" in the cancer setting: The Psycho-Oncology Consultation Model of patient care. Journal of Clinical Psychology in Medical Settings, 17, 249-257. https://doi.org/10.1007/s1088 0-010-9208-1.

Duffy, R. D., Foley, P. F., Raque-Bodgan, T. L., Reid-Marks, L., Dik, B. J., Castano, M. C., \& Adams, C. M. (2012). Counseling psychologists who view their careers as a calling: A qualitative study. Journal of Career Assessment, 20(3), 293-308. https://doi. org/10.1177/1069072711436145.

France, C. R., Masters, K. S., Belar, C. D., Kerns, R. D., Klonoff, E. A., Larkin, K. T., ... Thorne, B. E. (2008). Application of the competency model to clinical health psychology. Professional Psychology: Research and Practice, 29, 573-580. https://doi. org/10.1037/0735-7028.39.6.573.

Granek, M., Economou, D., Ferrell, B., \& Bhatia, S. (2007). Preparing professional staff to care for cancer survivors. Journal of Cancer Survivorship, 1, 98-106. https://doi.org/10.1007/s1176 4-007-0008-z.

Hill, C. E., Knox, S., Thompson, B. J., Williams, E. N., Hess, S., \& Ladany, N. (2005). Consensual qualitative research: An update. Journal of Counseling Psychology, 52(2), 196-205. https://doi. org/10.1037/0022-0167.52.2.196.

Hill, C. E., Thompson, B. J., \& Williams, E. N. (1997). A guide to conducting consensual qualitative research. The Counseling Psychologist, 25(4), 517-572. https://doi.org/10.1177/0011000097 254001.

Hoge, M., \& Roth, A. J. (2015). Training psychiatrists and psychologists in psycho-oncology. In J. C. Holland, W. S. Breitbart, P. B. Jacobson, M. J. Loscalzo, R. McCorkle \& P. N. Butow (Eds.), Psycho-oncology (3rd ed., pp. 684-689). New York: Oxford University Press.

Ito, J. K., \& Brotheridge, C. M. (2001). An examination of the roles of career uncertainty, flexibility, and control in predicting emotional exhaustion. Journal of Vocational Behavior, 59(3), 406-424. https ://doi.org/10.1006/jvbe.2001.1800.

Karoly, P. (1991). On the robustness and flexibility of clinical health interventions. In C. R. Snyder \& D. R. Forsyth (Eds.), Handbook of social and clinical psychology: The health perspective (pp. 717-736). New York: Pergamon Press.

Kerns, R. D., Berry, S., Frantsve, L. M. E., \& Linton, J. C. (2009). Life-long competency development in clinical health psychology. Training and Education in Professional Psychology, 3(4), 212-217. https://doi.org/10.1037/a0016753.

Kracen, A. C. (2018). Opening remarks. In A. Kracen (Chair). Challenges, sustaining factors, rewards, and training recommendations: Findings from a qualitative study of 20 psychologists with experience working in oncology. Symposium conducted at the annual meeting of the American Psychosocial Oncology Society, Tucson, AZ.

Lent, R. W., \& Brown, S. D. (2013). Understanding and facilitating career development in the 21 st century. In S. D. Brown \& R. W. Lent (Eds.), Career development and counseling (pp. 1-26). Hoboken: Wiley. 
Little, V. (2017). Workforce and performing provider system. Retrieved from SAMHSSA_HRSA Center for Integrated Health Solutions. Recruitment and retention of behavioral health providers: https:// www.integration.samhsa.gov/about-us/Recruitment_and_Reten tion_of_Behavioral_Health_Providers_Presentation.pdf.

London, M. (1993). Relationships between career motivation, empowerment and support for career development. Journal of Occupational and Organizational Psychology, 66(1), 55-69.

Martin, M. M., \& Rubin, R. B. (1995). A new measure of cognitive flexibility. Psychological Reports, 76(2), 623-626.

Mayer, D. (2018). The survivorship tsunami: How will we be able to deliver psychosocial care to those in need? Tuscon: Plenary presented at the American Psychosocial Oncology Society Annual Convention.

Medland, J., Howard-Ruben, J., \& Whitaker, E. (2004). Fostering psychosocial wellness in oncology nurses: Addressing burnout and social support in the workplace. Oncology Nursing Forum, $31(1), 47-54$.

Mehnert, A., Hartung, T. J., Friedrich, M., Vehling, S., Brähler, E., Härter, M., ... Koch, U. (2018). One in two cancer patients is significantly distressed: Prevalence and indicators of distress. Psycho-oncology, 27(1), 75-82. https://doi.org/10.1002/pon.4464.

Mitchell, K. E., Levin, A. S., \& Krumboltz, J. D. (1999). Planned happenstance: Constructing unexpected career opportunities. Journal of Counseling and Development, 77(2), 115-124.

National Cancer Institute (2018). Cancer statistics. Retrieved from https://www.cancer.gov/about-cancer/understanding/statistics.

Neimeyer, G. J., Taylor, J. M., Rozensky, R. H., \& Cox, D. R. (2014). The diminishing durability of knowledge in professional psychology: A second look at specializations. Professional Psychology: Research and Practice, 45(2), 92-98. https://doi.org/10.1037/ a0036176.
Spangler, P. T., Liu, J., \& Hill, C. E. (2012). Consensual qualitative research for simple qualitative data: An introduction to CQR-M. In C. E. Hill \& C. E. Hill (Eds.), Consensual qualitative research: A practical resource for investigating social science phenomena (pp. 269-283). Washington, D.C.: American Psychological Association.

Turner, J. (2010). Working as a multidisciplinary team. In D. Kissane, B. Bultz, P. Butow \& I. Finlay (Eds.), Handbook of communication in oncology and palliative care (pp. 245-257). London: Oxford University Press.

Villablanca, A. C., Beckett, L., Nettiksimmons, J., \& Howell, L. P. (2011). Career flexibility and family-friendly policies: An NIHfunded study to enhance women's careers in biomedical sciences. Journal of Women's Health, 20(10), 1485-1496. https://doi. org/10.1089/jwh.2011.2737.

Weick, K. E., \& Berlinger, L. R. (1989). Career improvisation in self-designing organizations. In M. B. Arthur, D. T. Hall \& B. S. Lawrence (Eds.), Handbook of career theory (pp. 313-328). Cambridge: Cambridge University Press.

World Health Organization (2008). The world health report 2006: Working together for health. Retrieved from http://www.who.int/ whr/2006/whr06_en.pdf?ua=1.

Canadian Association of Psychosocial Oncology. (n.d.). What is psychosocial oncology? Retrieved from https://www.capo.ca/patie nt-family-resources/what-is-psychosocial-oncology/.

Publisher's Note Springer Nature remains neutral with regard to jurisdictional claims in published maps and institutional affiliations. 